\title{
EDUCAÇÃO AO LONGO DA VIDA NAS POLÍTICAS EDUCACIONAIS E A PRETENDIDA AUSÊNCIA DA HISTÓRIA
}

\author{
Marilda Merência Rodrigues \\ Universidade Federal da Fronteira Sul - UFFS
}

\section{RESUMO}

No século XX, vimos emergir na UNESCO a expressão "educação ao longo da vida" como um paradigma educacional a ser alcançado. Suas filiações históricas remontam à década de 1960, quando se anunciaram as perigosas potencialidades da crise mundial da educação. $\mathrm{Na}$ década seguinte, essa crise apareceu sob a forma de ameaça de desequilíbrio do corpo social. Dissemina-se, nas próximas décadas, o ideário de um novo projeto de educação para o século XXI como antídoto para os "perigos" do desemprego e rupturas sociais. Evoca-se uma educação ao longo da vida capaz de promover o respeito às necessidades e diferenças individuais, de responder à democratização da educação e se constituir como chave de acesso ao século XXI. Tal perspectiva educacional se coaduna com o projeto histórico disseminado pela UNESCO, cujo alicerce tem sido a construção de um sujeito pacífico e tolerante, consoante à política contemporânea de segurança mundial para o sistema capitalista. Analisa-se, no presente trabalho, que tal paradigma educacional apoiase numa concepção de tempo e história que eterniza o presente, cuja conjuntura histórica é descrita como inexorável, dominada pela globalização, pela dependência e subordinação dos conhecimentos às novas economias do conhecimento.

Palavras-chave: políticas educacionais; educação ao longo da vida; UNESCO.

\section{LIFELONG LEARNING IN EDUCATION POLICIES AND THE INTENDED ABSENCE OF HISTORY}

\begin{abstract}
In the twentieth century we saw the expression "lifelong learning" emerge in UNESCO, as an education paradigm to be reached. Its historical filiations date back to the 1960s when the dangerous potential of the global crisis of education is advertised. In the following decade this mismatch appears in the form of a threat to the imbalance of the social body. In the next decades the ideology of a new education project for the twenty-first century spreads, as an antidote to the "dangers" of unemployment and social breakdown. A lifelong learning is evoked, one that promotes respect for individual needs and differences, responds to the democratization of education and represents an access key to the twentieth century. This educational approach is consistent with the historical project disseminated by UNESCO, whose foundation is built on a peaceful and tolerant basis, in line with the contemporary politics of global security for the capitalist system. It is analyzed in this study that this educational paradigm is based on a conception of time and history that perpetuates the present, whose historical juncture is described as relentless, dominated by globalization, dependence and subordination of knowledge to the new knowledge economies.
\end{abstract}

Keywords: education policies; lifelong learning; UNESCO. 


\section{Introdução}

No século XX, vimos emergir, nos canais de difusão internacionais da UNESCO, a expressão "educação ao longo da vida" como um paradigma educacional a ser alcançado. Suas filiações históricas remontam ao ano de 1967, quando se anunciavam as perigosas potencialidades da crise mundial da educação. Na década seguinte, essa crise, identificada como um desajustamento, apareceu sob a forma de ameaça de desequilíbrio do corpo social ou de desumanização, cujo enfrentamento dar-se-ia por uma educação coextensiva à vida. Nas décadas subsequentes, dissemina-se o ideário de um novo projeto de educação para o século XXI como antídoto para os "perigos" do desemprego e rupturas sociais, e de um sujeito que deverá aprender a ser, a fazer, a conhecer, a viver e a empreender. Para isso, evocam-se três eixos de argumentação sobre a perspectiva educacional fundamentada na educação ao longo da vida ${ }^{1}$ : a) como mecanismo de promoção do respeito às necessidades e diferenças individuais; b) como instrumento de democratização da educação; c) como chave de acesso ao século XXI, capaz de promover a participação do sujeito na "modernidade global".

Em que pesem os argumentos "inclusivos" sobre os quais a referida perspectiva educacional tem sido apresentada, a concepção de educação que a engendra se coaduna com o projeto histórico disseminado pela UNESCO ao longo de sua história, cujo alicerce tem sido a construção de um sujeito pacífico e tolerante, consoante à política contemporânea de segurança mundial para o sistema capitalista. Desse modo, seus aportes teóricos apontam para uma concepção de tempo e história que eterniza o presente, uma conjuntura histórica descrita como inexorável, dominada pela globalização, pelo contínuo desenvolvimento tecnológico, pela dependência e subordinação dos conhecimentos às novas "economias do conhecimento". Promove-se uma expulsão da "utopia" do campo da história, visando à construção de uma nova subjetividade, de um sujeito em eterna obsolescência.

É assim que se apresenta o tema central deste trabalho, a pretendida ausência da história no âmbito das políticas educacionais, notadamente no projeto de educação ao longo da vida proposto por organismos internacionais. Para aprofundá-lo, nos deteremos sobre dois elementos de sua compleição: os argumentos centrais sobre os quais se assenta a noção de educação ao longo da vida; o entrelaçamento entre a concepção de educação e história, que expressam o sujeito almejado no horizonte desse projeto educacional.

\section{Os reiterados argumentos em torno da educação ao longo da vida}

O primeiro eixo de argumentação desenvolve-se em torno da inclusão e reconhecimento de diferenças. Nele a educação ao longo da vida é descrita como possibilidade de atendimento e respeito às necessidades e diferenças individuais, na medida em que permitiria/viabilizaria percursos individuais dos jovens frente às incertezas do futuro, ao proporcionar "locais propícios à aprendizagem e à descoberta, fornecer-lhes meios para refletirem e prepararem o futuro, diversificar os percursos em função das suas capacidades, e agir, sempre, de modo que as suas perspectivas não saiam goradas e possam, a qualquer momento, retomar ou corrigir o percurso iniciado" (DELORS, 1998, p. 29).

Vincula-se a esse raciocínio o segundo eixo de argumentação, o de que a educação ao longo da vida se constitui numa resposta à democratização da educação para todos, entendida como exigência democrática e como resposta ao atendimento de igualdade de 
oportunidades a ser efetivada na prática. Conforme o relatório Educação: um tesouro a descobrir (DELORS, 1998, p. 106),

o princípio da igualdade de oportunidades constitui um critério essencial para todos os que se dedicam à progressiva concretização das diferentes vertentes da educação ao longo de toda a vida. Correspondendo a uma exigência democrática, seria justo que este princípio estivesse presente, de maneira formal, em modalidades mais flexíveis de educação, através das quais a sociedade apareceria, logo de saída, como responsável pela igualdade de possibilidades de escolarização e de formação posterior oferecidas a cada um no decurso da sua vida, sejam quais forem os desvios ou incertezas do seu percurso educativo.

O terceiro eixo de argumentação assimila tal perspectiva educacional à prerrogativa de entrada e participação do sujeito na "modernidade global" como condição de desenvolvimento dos sujeitos individualmente e dos países diante das novas exigências da sociedade do conhecimento, entendida como "uma das chaves de acesso ao século XXI", "como resposta aos desafios decorrentes das rápidas transformações" (DELORS, 1998, p. 19). A educação ao longo é situada como um conceito que ultrapassaria o sentido de preparação para a aprendizagem de uma profissão e atuaria como meio de pôr o sujeito em condições de adquirir competências para o enfrentamento de "numerosas situações, muitas delas imprevisíveis" (DELORS, 1998, p. 20). Desse modo, assenta-se na ideia de que o século XXI exigirá "responsabilidade pessoal, na realização de um destino coletivo" (DELORS, 1998, p. 20). A educação permanente é indicada como meio de construção de uma sociedade civil ativa, no sentido de que cada um possa "assumir a sua parte de responsabilidade como cidadão ao serviço de um destino autenticamente solidário" (DELORS, 1998, p. 63).

Decorrente desse raciocínio, outra proposição veiculada é a de que as tecnologias da informação e da comunicação se constituiriam como vetores de uma sociedade educativa, possibilitando uma abertura à educação não-formal e, desse modo, seriam repensados os tempos de aprendizagem de cada indivíduo, o lugar e a função dos sistemas educativos, de modo que se considerasse a "perspectiva de uma educação prolongada pela vida afora" (DELORS, 1998, p. 66). A sociedade educativa ofereceria "múltiplas oportunidades de aprender na escola como na vida econômica social e cultural" (DELORS, 1998, p. 166). Para a sua consecução, são enfatizadas as necessidades de multiplicação de acordos e contratos de parceria "com as famílias, o meio econômico, o mundo associativo, os atores da vida cultural etc." (DELORS, 1998, p. 166). Além disso, propõe-se a readaptação dos sistemas educativos formais e a flexibilização curricular, argumentando-se que a instabilidade dos tempos modernos "perturbaram os espaços educativos tradicionais: igreja, família, comunidade de vizinhos" (DELORS, 1998, p. 107). As necessidades educativas teriam sido de tal forma alteradas pelo progresso da ciência e da tecnologia que a pertinência dos sistemas de educação teria sido colocada em questão, considerados pouco flexíveis e incapazes de trabalhar na lógica de antecipação para preparar competências para o futuro (DELORS, 1998).

O espírito de iniciativa e a autonomia são propagados como suportes da criatividade e da inovação, entendidas como indispensáveis aos indivíduos. Essas características, conforme apresenta o relatório Educação: um tesouro a descobrir, podem ser ameaçadas por uma certa estandardização dos comportamentos individuais. "O século XXI necessita desta diversidade de talentos e de personalidades, mais ainda de pessoas excepcionais, igualmente essenciais em qualquer civilização" (DELORS, 1998, p. 100). Além disso, uma 
das ideias centrais defendidas é a de que "a formação profissional deve conciliar dois objetivos divergentes: a preparação para os empregos existentes atualmente e uma capacidade de adaptação a empregos que ainda nem sequer podemos imaginar" (DELORS, 1998, p. 136).

Ancorada no argumento democratizante e aparentemente respeitoso de atendimento às necessidades de percursos individuais, essa perspectiva educacional é proclamada como novo eldorado, capaz de concretizar a estratégia de educação para todos, apresentando-se sob um atraente véu democrático, em que "todos os lugares e momentos" se constituiriam em importantes situações de aprendizagem para o indivíduo do século XXI, definido e idealizado como um protagonista cercado por "escolhas", em uma "cesta repleta de variedades de modo que todos e todas as diferenças possam ser acomodadas de modo a evitar todo antagonismo" (AHMAD, 1999, p. 4), mesmo que tais escolhas variem entre conhecer o mundo via televisão, ser um empreendedor e/ou manter-se continuamente na condição de empregável. Preocupa-nos, justamente, os limites dessas escolhas, pois, como lembra Mèszáros (2007, p. 68), "o capital não é simplesmente uma entidade material. Cumpre pensarmos o capital como um modo historicamente determinado de controle da reprodução sociometabólica".

\section{A pretendida ausência da História}

Ao recolocar a pergunta filosófica clássica "o que é o homem?" Gramsci a reelabora sob o ponto de vista da história, incluindo nesse questionamento a relação homem, espaço e tempo: "o que é cada homem singular em cada momento singular" (GRAMSCI, 1999, p. 412). Desse modo, a pergunta inicial assume para esse pensador o significado:

O que é que o homem pode se tornar, isto é, se o homem pode controlar seu próprio destino, se ele pode "se fazer", se pode criar a sua própria vida. Digamos, portanto, que o homem é um processo, precisamente o processo de seus atos. (GRAMSCI, 1999, p. 412).

Assim posto, o presente é entendido como um campo de possibilidades que pressupõe, nos termos de Moraes (2007), um futuro aberto. Contudo, esta autora apresenta uma importante denúncia, "o conhecimento e a ciência estão sob ameaça, notadamente as ciências humanas e sociais" (MORAES, 2007, p. 1), e essa ameaça deve-se, sobretudo, ao contexto de ceticismo epistemológico e de relativismo ontológico que se expressam também na perspectiva de educação consubstanciada na denominação "ao longo da vida", visto tratar-se de um enunciado temporal que orienta e conforma determinado modo de conceber a educação e os sujeitos na sua relação com o passado, presente e futuro, expressando nessa relação o sentido atribuído à história.

Apresentados como narrativa de validade pretensamente universal, os documentos analisados, em especial os da década de $1990^{2}$, convergem em suas percepções sobre a conjuntura histórica, descrita como uma realidade dominada pela globalização, pelo contínuo desenvolvimento tecnológico e pelas mudanças aceleradas, bem como pela intrínseca dependência e subordinação de conhecimentos específicos às "novas economias da Era do conhecimento" (COMISSÃO DAS COMUNIDADES EUROPÉIAS, 2000, p. 7). Nessa análise, repetidas vezes afirma-se a necessidade de inovação, mudança, adaptação, decorrentes de profundas alterações na sociedade contemporânea, ora denominada de "sociedade da informação", ora de "sociedade do conhecimento". Em ambas, as 
denominações são qualificadas positivamente, dado o suposto caráter democratizante assumido pelos sistemas de informação, e tratadas num tom de naturalidade e obviedade, bem ao gosto das ideologias, pois, como lembra Warde (1990, p. 6), "na História, as ideologias tomam a forma de conceitos, categorias, cronologias ..., ou seja, já se apresentam sob a forma de conhecimento".

Assim, o termo sociedade do conhecimento e seus similares são identificados à emergência de um "mundo novo", à "interdependência planetária", explicados como fatores decorrentes, até impostos, como sugere o relatório da Comissão Internacional para a Educação da UNESCO (DELORS, 1998, p. 35), "pela abertura das fronteiras econômicas e financeiras, impelida por teorias de livre comércio, reforçada pelo desmembramento do bloco soviético, instrumentalizada pelas novas tecnologias da informação"

Também a expressão globalização é considerada por Ahmad (1999, p. 5) "altamente ideológica e enquanto tal refere-se a coisas diversas" 3 . Na esteira desse caráter ideológico, grassa a percepção de inevitabilidade do "destino" do mundo, expressa na ideia de que "grande parte do destino de cada um de nós, quer o queiramos quer não, joga-se num cenário em escala mundial" (DELORS, 1998, p. 35). Da mesma forma, as prescrições/soluções para a educação e para a "crise" são anunciadas como "orientações válidas, tanto em nível nacional como mundial" (DELORS, 1998, p. 12). Eis o caráter altamente pernicioso da tese da globalização, pois inclui no rol de suas justificações a ideia de que representa um processo de unificação do capital mediante a erosão das fronteiras nacionais, argumento esse veementemente criticado por Wood (2001), que nele identifica um dos grandes perigos das teses da globalização, isto é, o esvaziamento promovido no campo da política pelas interpretações desse fenômeno como algo inevitável e inexorável.

Entretanto, apesar do entusiasmo manifestado acerca da "modernidade global", tem-se também descrito um sentimento de vertigem vivido pelos contemporâneos como uma sensação coletiva, uma certa inquietude, um "mal-estar causado pela falta de visão clara do futuro", "a incerteza sobre o próprio destino" (DELORS, 1998, p. 45), visto que o futuro é identificado como o lugar das incertezas e inseguranças. Embora o mundo seja nominado como "uma caixa de ressonância das crises industriais dos países mais desenvolvidos" (DELORS, 1998, p. 38) ou conjunturalmente interdependentes, é o sujeito, individualmente, quem é chamado a dar respostas a esse mundo qualificado de "multirriscos", cujos elementos ainda por decifrar são entendidos como "uma das características dos finais do século XX, que perturba e inquieta profundamente" (DELORS, 1998, p. 44). Desse modo, a "vertigem" do sujeito do século XXI é descrita como uma espécie de frustração diante da impossibilidade de responder às exigências da "modernidade global".

Chauí (1980), ao discutir a concepção marxista de ideologia, observa, acerca da obra A ideologia alemã, que esta "tem como objeto privilegiado um pensamento historicamente determinado, qual seja, os dos pensadores alemães posteriores a Hegel [...]" (CHAUI, 1980, p. 14), evidenciando que Marx e Engels não separam a produção das ideias das condições sociais e históricas nas quais são produzidas, aliás, esta separação "é o que caracteriza a ideologia" (CHAUI, 1980, p. 14). Tal compreensão nos permite aprofundar o entendimento sobre o discurso veiculado em documentos de política educacional, levando à percepção sobre o modo como a vertigem do sujeito do final do século XXI é descrita, isto é, desterritorializada, dissociada das origens que objetivam o modo de ser.

Para o historiador Ciro Flamarion Cardoso, o sujeito da atualidade vive uma espécie de desnorteamento, fenômeno que teria suas raízes determinadas por dois fatores: uma "superabundância dos acontecimentos e, mais em geral, do excesso de informação que nos ameaça em nosso presente" (CARDOSO, 2006, p. 4) e, sobretudo, a insistente 
reafirmação da noção de que "o mundo em que vivemos é a tal ponto distinto de tudo o que o precedeu, além de transformar-se a um ritmo tão alucinante, que a história se teria tornado irrelevante" (CARDOSO, 2006, p. 4).

Veiculados como vozes consoantes e localizadas supostamente numa esfera "atemporal" e "apolítica", os documentos de políticas educacionais referidos, expressam uma compreensão de história que estabelece "papéis" bem definidos para os sujeitos. É, portanto, no encontro dessas duas perspectivas aparentemente paradoxais, quais sejam, a subordinação do destino de cada um ao destino do "mundo global" e a responsabilidade atribuída ao indivíduo em produzir respostas às exigências desse "novo mundo", que reside o sentido de história subjacente ao projeto de educação ao longo da vida.

Insegurança, incerteza, vertigem e aceleração teriam gerado "um novo projeto de educação para o século XXI", apropriado às transformações "novas" ou sem precedentes; um quadro de referência de políticas a longo prazo, capaz de fornecer ao indivíduo condições de lidar com a incerteza do presente e do futuro; a possibilidade de "construção contínua da pessoa" (DELORS, 1998, p. 18); e resposta ao questionamento "[...] como adaptar a educação ao trabalho futuro quando não se pode prever qual será a sua evolução?" (DELORS, 1998, p.93). Eis aqui as atribuições conferidas à educação ao longo da vida, reconhecida como "uma questão que afeta o futuro de todos, de forma perfeitamente individualizada" (COMISSÃO DAS COMUNIDADES EUROPÉIAS, 2000, p. 3-4).

A análise de conjuntura, bem como as proposições que orientam a política educacional guiada pela noção de educação ao longo da vida, não apenas demarcam um projeto para o presente e/ou para o futuro, como também engendram uma disputa pelo registro de uma temporalidade (REIS, 1998), visto que "quando se vive e se age, fazem-se opções por valores, i. e., por uma certa periodização, por uma certa direção, por um certo passado e um certo futuro" (REIS, 1998, p. 29). Isso nos leva a um questionamento crucial: qual é o "modo de durar", na acepção do historiador Reis, instituído pela política educacional fundamentada na educação ao longo da vida? Em outras palavras, quais são os limites e/ou possibilidades admitidos para o percurso da vida do indivíduo sob a égide de tal projeto de educação?

Há, na documentação analisada, uma conformidade com a conjuntura histórica que evoca a perda do sentido de qualquer questionamento radical quanto ao futuro ou suas possibilidades fora do cenário (destino) previamente moldado e pensado como possível, promovendo-se uma expulsão da "utopia" do campo da história. Saviani (1998, p. 11-12) compreende que "o debate historiográfico tem profundas implicações para a pesquisa educacional, vez que o significado da educação está intimamente entrelaçado ao significado da História". Entendemos que, ao produzirem prospecções e/ou prescrições sobre a educação, os documentos, em especial os produzidos nos anos de 1990, produzem um determinado modo de escrita e apreensão da história que convergem para importantes aspectos metodológicos e epistemológicos comuns ao movimento denominado de Nova História. E o que comporia a chamada Nova História e a que ela se oporia?

A Nova História pode ser entendida como uma das fases do movimento historiográfico da chamada Escola dos Annales, originada na década de 1920, ancorada, segundo Cardoso (1997, p. 7-8) especialmente em oito pontos básicos: 1) Na crença do caráter científico da história, conduzindo à afirmação da necessidade de passar de uma 'história-narração' a uma 'história-problema' mediante a formulação de hipóteses de trabalho. 2) No debate crítico com as ciências sociais, sem reconhecer fronteiras estritas e definitivas entre essas duas áreas, importando de lá problemáticas, conceitos, métodos e técnicas. 3) $\mathrm{Na}$ ambição de formular uma síntese histórica global do social, explicando a 
vinculação existente entre técnicas, economia, poder e mentalidades, e também as oposições e as diferenças de ritmo e fase entre os diferentes estratos do social. 4) No abandono da história centrada em fatos isolados e também numa abertura preferencial aos aspectos coletivos, sociais e repetitivos, substituindo a fixação em indivíduos, elites e fatos "irrepetíveis". 5) Na diminuição da ênfase sobre as fontes escritas, utilizando-se da história oral, dos vestígios arqueológicos, da iconografia, entre outros. 6) $\mathrm{Na}$ tomada de consciência da pluralidade de temporalidades: a curta duração dos acontecimentos, o tempo médio (e múltiplo) das conjunturas, a longa duração das estruturas. 7) $\mathrm{Na}$ preocupação com o espaço. 8) $\mathrm{Na}$ percepção do historiador como um homem do seu tempo, e da história como "ciência do passado" e "ciência do presente" ao mesmo tempo.

Para Saviani (1998, p. 9), os objetivos dessa escola historiográfica podem ser entendidos como a "busca de superação dos limites da historiografia tradicional de fundo positivista até então dominante", no entanto, chama a atenção para o fato de que não se trata de uma escola historiográfica de caráter homogêneo e linear. Nesse sentido, cabe salientar que as designações História Tradicional e Nova História tendem a acolher sob seus rótulos diferentes correntes de pensamento. Estende-se sob o domínio da História Tradicional não apenas o positivismo, o evolucionismo, o historicismo, mas também o marxismo. Já a Nova História tende a ultrapassar o sentido de uma corrente da Escola dos Annales, assumindo vulgarmente o status de guarda-chuva de múltiplas formas de escrita da história, com todos os "culturalismos" e "pós-modernismos".

Para Burke (1997, p. 10), a coesão do movimento da Nova História se daria muito mais naquilo a que se opõe, definindo-a como "a história escrita como uma reação deliberada contra o 'paradigma' tradicional [...]". Assim, apresenta seis características do paradigma tradicional de História: 1) No paradigma tradicional a história diz respeito essencialmente à política. Em oposição, a Nova História teria se interessado por toda atividade humana, pautada na base filosófica de que "a realidade é social ou culturalmente constituída" (BURKE, 1997, p. 11). 2) O paradigma tradicional se relaciona à forma de escrita da história. A Nova História estaria mais preocupada com a análise das estruturas (mental, geográfica, cultural), superando a história tradicional como uma narrativa dos acontecimentos. O autor compreende que a Nova História rejeita a história dos acontecimentos, conferindo importância maior às mudanças de longo prazo ou à longa duração. 3) A história tradicional ofereceria uma visão de cima, focando grandes feitos dos grandes homens, em oposição a Nova História, a "história vista de baixo", que teria conferido atenção à história da "cultura popular". 4) No paradigma tradicional, a história deveria ser baseada em "registros oficiais, emanados do governo e preservados em arquivos", ao passo que a Nova História atribuiria o mesmo valor a todos os tipos de fontes (BURKE, 1997, p. 13). 5) O paradigma tradicional se refere ao modo de inquirição do historiador ao objeto de estudo e às suas fontes. A lógica que permeia a narrativa baseia-se no princípio de causalidade, assim, Burke (1997) compreende que a simplicidade do questionamento nesse paradigma levaria, também, à simplificação da explicação histórica esperada. Em oposição, a Nova História ampliaria o conjunto de questionamentos, com perguntas sobre as particularidades (do sujeito, das micro-histórias), o que levaria a uma pluralidade de respostas, à história no plural. 6) Relaciona-se à objetividade da História. No paradigma tradicional, conforme o autor, "a tarefa do historiador é apresentar aos leitores os fatos, ou, como apontou Ranke [...] dizer 'como eles realmente aconteceram"” (BURKE, 1997, p. 15), no âmbito da Nova História, o objetivo não é apreender a História em sua totalidade, mas de compreendê-la em sua relatividade, por meio de seus fragmentos e singularidades. 
Compreendemos que a escrita da história da educação não fica incólume ao debate das teorias da História, visto ser um debate cujas raízes não dizem respeito essencialmente ao destino de uma disciplina científica, mas atravessam as diferentes ciências sociais, contrapondo-se essencialmente às propostas da Ilustração. Para Moraes (1996), o chamado pós-moderno não expressa um corpo conceitual coerente e unificado, ao contrário, em seu conjunto "coloca sob suspeita a confiança iluminista em uma razão capaz de elaborar normas, construir sistemas de pensamento e de ação e de habilidade racional de planejar de forma duradoura a ordem social e política" (MORAES, 1996, p. 3). Tais controvérsias sobre os paradigmas das ciências sociais e da história incidem no debate da educação e indicam "sinais de inquietação e perplexidade em vista da emergência de novas perspectivas teóricas e metodológicas, de novos objetos e abordagens" (MORAES, 1996, p. 1).

Se a História teve seu escopo ampliado, a Educação também sofreu esse "alargamento", tanto no sentido atribuído às novas possibilidades de pesquisa da história da educação promovidas por esse novo paradigma, quanto nas outras características desse movimento historiográfico. A educação ao longo da vida expressa também esse reposicionamento dos paradigmas das ciências sociais, em cujas justificações é possível encontrar importantes consonâncias com as características da Nova História.

O primeiro aspecto diz respeito ao próprio "alargamento" do sentido de educação e da consequente importância atribuída ao âmbito cultural, localizado em múltiplos tempos e espaços alternativos, assumindo centralidade na tarefa educativa. $\mathrm{Na}$ abordagem da educação ao longo da vida, retoricamente, todos os tempos e espaços são considerados lugares de aprendizagem, numa sociedade educativa em que todos podem ensinar, principalmente, a mídia e seus recursos tecnológicos e mercadológicos, expressão do novo potencial "alargado" da educação, marcado pela desimportância do político, visto que "o domínio cultural, criador do social, torna-se o lugar central dos conflitos, lugar das contradições, núcleo de inteligibilidade de uma sociedade" (DOSSE, 1992, p. 176). Nessa lógica do domínio cultural, instalado passivamente na realidade dessa sociedade educativa, dos meios de comunicação de massa, lembra Dosse (1992, p. 14), "a informação renova-se a cada dia, e um conjunto de acontecimentos ao mesmo tempo rápido e urgente desenvolve-se sobre a vasta cena mundial; isso nos oferece a imagem de uma história que se acelera ao mesmo tempo em que nos escapa. Nós mais a sofremos do que a vivemos"

Outro aspecto que avizinha a narrativa em torno da educação ao longo da vida à escrita da Nova História é a perspectiva de aproximação das massas, de "popularização", respondendo ao grande slogan dos anos de 1990, "educação para todos", veiculada como importante mecanismo democrático, na medida em que confere, supostamente, o mesmo valor a todos os lugares de aprendizagem e a todos os percursos de aprendizagem. Alinhase, por essa via, a uma pretensa história "vista de baixo". Uma das principais aproximações a essa forma historiográfica presente na documentação analisada reside numa importante mudança epistemológica, qual seja, a exaustiva negação da objetividade da História e, consequentemente, a negação de sua apreensão "como uma totalidade ordenada e coerente" (MORAES, 1996, p. 3), capaz de ser apreendida pelas suas múltiplas determinações. Sob tal perspectiva, impera a impossibilidade de pensar o sentido da história ou quaisquer possibilidades de construção de diferentes projetos históricos, visto que, para os defensores da ordem vigente, segundo Mészáros (2007), o tempo só pode ter uma dimensão: a do eterno presente.

Para Cardoso (1997, p. 3), a Nova História é a "história em migalhas", "preocupada centralmente com a diversidade dos objetos e a alteridade cultural, entre sociedades e dentro de cada uma delas" e o paradigma ameaçado em sua hegemonia é o "moderno" ou 
"iluminista", cujas vertentes mais influentes e prestigiosas, resguardadas importantes diferenças entre si, foram o marxismo e o grupo dos Annales no período de 1929-1969. O autor compreende que as principais críticas ao paradigma iluminista se dão em dois planos: via um arcabouço filosófico e epistemológico e no campo da filosofia da ciência, em oposição ao evolucionismo e à noção de progresso, apoiadas em argumentos fornecidos pela trágica história do século XX, e sustentadas por uma desilusão com a história, a modernização, a ciência, etc, resultando num abandono da ideia de progresso. Esse conjunto de críticas desemboca

na contestação da possibilidade de explicação racional do social, do humano, que não passaria de uma ilusão cientificista desprovida de conteúdo efetivo, mas perniciosa porque em torno dela se constituiria um saber terrorista a serviço do poder [...] e evacuador de outros saberes (CARDOSO, 1997, p. 10).

O desafio mais importante a ser enfrentado pela ruptura do paradigma iluminista refere-se ao sentido ou ausência de sentido da história: "refiro-me às afirmações, correntes hoje em dia, da impossibilidade de surgimento de novas ideologias globais e novas teorias holísticas do social, no que vem sendo chamado de "fim da história"' (CARDOSO, 1997, p. 12-13).

De acordo com Reis (2005, p. 53), o quadro do que seria uma historiografia dominada pela temporalidade pós-moderna ainda não está estabelecido, pois "ainda vivemos esse processo e não conhecemos bem o seu significado". Considera, entretanto, a existência neste contexto de uma supremacia da esfera cultural que "aparece no interior de todas as outras esferas: a economia é uma forma histórica e particular de representar a produção da riqueza; a política é uma forma histórica e particular de representar o poder etc" (REIS, 2005, p. 58). Além disso, o autor identifica uma característica recorrente nessa historiografia, a constatação de que "tudo o que se soube até aqui parece ultrapassado e insuficiente" (REIS, 2005, p. 58).

Essa forma de lidar com o tempo e, consequentemente, com a história está presente na narrativa dos documentos em questão, nos quais o passado parece ser propositalmente "destruído", para usar o termo de Hobsbawm (1995), tendo sua importância ofuscada pelo caráter sempre inaugural do presente, dada a constatação da existência de "elementos novos que acentuam o perigo e, especialmente, o extraordinário potencial de autodestruição criado pela humanidade no decorrer do século XX” (DELORS, 1998, p. 96).

A destruição do passado discutida por Hobsbawm (1995) se expressa nos documentos estudados, em especial, de duas formas: 1) no sentido atribuído às novas tecnologias, vistas como responsáveis por lançar o sujeito numa nova era, enfatizadas como elementos que "fizeram a humanidade entrar na era da comunicação universal; abolindo as distâncias, concorrem muitíssimo para moldar a sociedade do futuro, que não corresponderá, por isso mesmo, a nenhum modelo do passado" (DELORS, 1998, p. 39); 2) no recorrente apelo a um "novo modelo" de educação, a superar um passado (impreciso) dos sistemas educacionais, passado associado a inflexibilidades e atitudes retrógradas. Nesse "novo modelo", o sujeito deverá se reinventar a cada dia num processo contínuo e ininterrupto de "correção" de seu percurso ao longo da vida, adaptando-se às necessidades do mercado e assumindo a culpa por ter feito escolhas equivocadas.

Consoante a essa perspectiva de futuro, a documentação examinada converge para um modo de pensar a política educacional fundamentada numa noção de história que concilia duas formas de apreensão temporal, a curta duração, o evento "explosivo", 
"novidade sonante", nos termos de Braudel (1992), a efemeridade dos acontecimentos, e a longa duração em que pode ser percebida e entendida a continuidade, as grandes permanências na história e "a mudança é enquadrada em uma permanência" (REIS, 1994, p. 27). Nesse caso, o sistema capitalista e a globalização ocupam lugares de metanarrativas, isto é, narrativas norteadoras, balizadoras do sentido da história, "grandes sínteses teóricas sobre a história, a sociedade e o ser humano" (DUARTE, 2001, p. 39). Por outro lado, embora essas metanarrativas circundem, norteiem, balizem a história na narrativa dos documentos, o ganha realce, é a efemeridade, a "novidade sonante", a inovação, a (auto) superação acelerada das tecnologias, a ideia de imaterialidade do trabalho e a perda de sua centralidade, que marcam significativamente o futuro como o lugar das incertezas, do desconhecido, traçando, de fato, um modo de escrita da história da educação que visa a eliminação do acontecimento, da política, do sujeito histórico.

A denominada História Tradicional, com sua temporalidade marcada pelo "acontecimental, do único, singular e irrepetível, linear, progressista e teleológica" (REIS, 1998, p. 30), foi julgada gradativamente incapaz, inadequada para apreender a história do século XX, consolidando-se, sob a influência das ciências sociais, uma abordagem estrutural do tempo histórico em oposição à abordagem teleológica da história. Para Reis (1998), com o conceito de estrutura social, as ciências sociais querem encontrar no mundo humano regularidades, estabilidades. Essa compreensão advinda das ciências sociais teria influenciado significativamente a forma de pensar e escrever a história, caracterizando uma busca pela "desaceleração dos tempos das sociedades" (REIS, 1998, p. 31).

A hipótese defendida por Reis (1998) é de que tanto as ciências sociais quanto os Annales, sob a influência daquela, representaram uma busca por estabilidade e harmonia, visando o "controle da mudança brusca, o controle da alteridade e irreversibilidade pela suspensão do devir e a construção da permanência, da identidade, da paz" (REIS, 1998, p. 42). Essa busca pelo domínio do evento se justificaria, segundo o autor, pela experiência da derrota vivida pelos países europeus no século XX, cuja história teria assinalado um grande evento, a finitude que, por sua vez, representa "a mudança, a instabilidade do tempo humano" (REIS, 1998, p. 32). Compreende que o novo modo de escrita e apreensão da história elaborado pelos Annales "procura organizar, racionalizar o inesperado, o intolerável" (REIS, 1998, p. 43). Significaria a busca por uma desaceleração do tempo das sociedades, um desestímulo à produção de eventos, sobretudo, "os produzidos pela enorme força material das massas. As massas [...] deveriam ficar de fora da produção do evento. Elas deveriam ficar confinadas à sua 'vida material', sem acesso ao evento, à produção da história" (REIS, 1994, p. 44).

\section{Considerações finais}

Entendemos que a noção de educação ao longo da vida é construída sobre estas duas percepções de duração: a curta e a longa duração, em outros termos, é construída na convergência da aceleração e desaceleração da história, numa expressão cabal de que "a única maneira de o capital se relacionar com a história em nosso tempo é abusar violentamente dela" (MĖSZÁROS, 2007, p. 26, grifos do autor). A pretensa "aceleração da história" se expressaria na percepção de conjuntura definida pelo caráter "demiúrgico da tecnologia" (CASTRO, 2004), em que o ritmo das pessoas, de produção dos conhecimentos, de aprendizado, de validade do conhecimento ou competência adquirida teria se tornado passado em seu presente.

Por outro lado, a noção de educação ao longo da vida evidencia a busca por uma "desaceleração da história", na medida em que trabalha com a percepção de imobilidade da 
estrutura e com um discurso altamente consolador, democratizante e equitativo, em que as diferenças são tratadas numa suposta horizontalidade, atuando como um poderoso constructo ideológico de antecipação/contenção de movimentos sociais à universalização de uma escola pública de qualidade, eclipsando possíveis vozes dissonantes, "exorcizando o risco", na expressão de Dosse (1992). Outro importante aspecto dessa "desaceleração da história" vincula-se à leitura de conjuntura descrita pela égide da imaterialidade do trabalho ou perda de sua centralidade na "sociedade da informação" e consequente aumento do tempo livre dos indivíduos. Nessa lógica, a política de educação ao longo da vida se inscreveria como uma importante forma de ocupação desse tempo livre, num processo de reestruturação e controle de hábitos, como uma forma de assegurar certa regularidade aos ritmos da vida.

\section{Referências}

AHMAD, Aijaz. Problemas de Classe e Cultura. In: WOOD, E. M; FOSTER, J.B. Em defesa da história: marxismo e pós-modernismo. Rio de Janeiro: Jorge Zahar Editor, 1999.

BRAUDEL, Fernand. Escritos sobre a historia. 2.ed. São Paulo: Perspectiva, 1992.

BURKE, Peter. A escola dos Annales (1929-1989): a revolução francesa da historiografia. São Paulo: Fundação Editora da Unesp, 1997.

CARDOSO, Ciro F. História e Paradigmas rivais. In: CARDOSO, C. F. \& VAINFAS, R. (orgs.). Domínios da história: ensaios de teoria e metodologia. Rio de Janeiro: Campus, 1997.

CASTRO, Ramón Peña. Escola e Mercado: a escola face a institucionalização do desemprego e da precariedade na sociedade colocada a serviço da economia, Perspectiva, Florianópolis, vol. 22, n. 01, p. 79-92, jan./jun. 2004.

CHAUÍ, Marilena. O que é ideologia. São Paulo: Brasiliense, 1980.

COMISSÃO DAS COMUNIDADES EUROPÉIAS. Memorando sobre Aprendizagem ao Longo da Vida. Documento de Trabalho dos Serviços da Comissão. Bruxelas, 30/10/2000. Disponível em: <http://eur-

lex.europa.eu/LexUriServ/LexUriServ.do?uri=COM:2006:0614:FIN:PT:PDF>. Acesso em: 22 de julho de 2004.

DELORS, Jacques (org.). Educação: Um tesouro a descobrir. Relatório para a UNESCO da Comissão Internacional sobre Educação para o século XXI. 2a Edição - São Paulo: Cortez, 1998.

DOSSE, François. A História em migalhas: dos "Annales" à "Nova História". São Paulo: Ensaio; Campinas: Editora da Universidade Estadual de Campinas, 1992.

DUARTE, Newton. Vigotski e o aprender a aprender: crítica às apropriações neoliberais e pós-modernas da teoria vigotskiana. 2. ed., Campinas, São Paulo: Autores Associados, 2001.

GRAMSCI, Antonio. Cadernos do Cárcere. Vol.1; edição e trad. Carlos N. Coutinho. Rio 
de Janeiro: Civilização Brasileira, 1999.

HOBSBAWM, E. J.. Era dos extremos: o breve século XX : 1914 - 1991 . 2. ed. São Paulo: Companhia das Letras, 1995.

MÉSZÁROS, István. O desafio e o fardo do tempo histórico: o socialismo no século XXI. São Paulo: Boitempo, 2007.

MORAES, Maria Célia M. . Os “pós-ismos” e outras querelas ideológicas. Perspectiva. Florianópolis, ano 14, n. 5, p. 45-60, jan./jun. 1996.

Indagações sobre o conhecimento no campo da educação. In: 30.

REUNIÃO ANUAL DA ANPEd, 30., 2007. Caxambu. Anais... Caxambu: ANPEd, 2007. 1 CD-ROM.

REIS, José Carlos. Nouvelle Histoire e Tempo Histórico: a contribuição de Febvre, Bloch e Braudel. São Paulo: ed. Ática, 1994.

.Os Annales: a renovação Teórico-Metodológica e "Utópica" da História pela reconstrução do tempo histórico. In: SAVIANI, D.; LOMBARDI, J. C.; SANFELICE, J. L. (Orgs.). História e História da Educação: o debate Teórico-Metodológico Atual. Campinas, SP: Autores Associados: HISTEDBR, 1998, p. 25-49.

História \& teoria: historicismo, modernidade, temporalidade e verdade. 2. ed. Rio de Janeiro: Ed. da FGV, 2005.

WOOD, Ellen Meiksins. Trabalho, Classe e Estado no capitalismo global. In: SEOANE, José e TADDEI, Emilio (Orgs.) Resistências Mundiais. De Seattle a Porto Alegre.

Petrópolis: Vozes, 2001. p. 99-121.

SAVIANI, Dermeval. O debate Teórico e Metodológico no campo da História e sua importância para a Pesquisa Educacional. In: SAVIANI, D.; LOMBARDI, J. C.; SANFELICE, J. L. (Orgs.). História e História da Educação: o debate Teórico-

Metodológico Atual. Campinas, SP: Autores Associados: HISTEDBR, 1998, p. 7-15.

\section{Notas}

1 A discussão aqui apresentada é parte integrante da tese defendida em 2008 no PPGE/UFSC, intitulada Educação ao Longo da Vida: a eterna obsolescência humana, sob a orientação da professora Olinda Evangelista. O presente artigo foi apresentado no V EBEM- Encontro Brasileiro de Educação e Marxismo, GT- 7 História e Marxismo, Florianópolis, 2011.

2 Note-se que as sínteses e conclusões aqui apresentadas resultam das análises empreendidas na Tese de Doutorado Educação ao longo da vida: a eterna obsolescência humana, cujas análises ancoraram-se em importantes documentos da UNESCO e da Comissão Européia no que concerne ao tema educação ao longo da vida, compreendendo desde documentos dos anos da década de 1960 até documentos de 2006. Dos referidos documentos, destacam-se como fontes imprescindíveis para a análise três publicações que podem ser consideradas marcos estruturantes para a disseminação da noção de educação ao longo da vida, quais sejam, A crise mundial da educação - uma análise sistêmica (1968); o relatório Aprender a ser - a educação do futuro (1972) e o relatório Educação um tesouro a descobrir (1996); documentos referentes ao Projeto Principal e ao Projeto Regional de Educação para a América Latina e Caribe (OREALC/UNESCO); Documentos da Comissão Européia, especialmente o Memorando sobre educação ao longo da vida (2000), o 
Livro Branco Um novo impulso à juventude européia (2001) e a Comunicação da Comissão Tornar o espaço europeu de aprendizagem ao longo da vida uma realidade (2001).

3 Para o autor, existem quatro significados recorrentes deste termo, indicativos de seu caráter ideológico: o primeiro diz respeito à interpretação, fornecida em caráter universal, de que com o fim da União Soviética e a queda do leste europeu existe um único caminho para o desenvolvimento societário, ou seja, o do capitalismo imperialista; o segundo diz respeito à mobilidade do capital e das mercadorias, à expansão comercial nacional/internacional e à especulação financeira internacional possibilitadas por tecnologias de comunicações aperfeiçoadas, à implementação cultural por meio do poder de inserção midiática internacional e a produção e gerenciamento fragmentário de empresas multinacionais que podem produzir um mesmo produto em vários locais; o terceiro indica que o termo globalização "é também um eufemismo para o fato de que um punhado de instituições de caráter imperialista - o Banco Mundial, o FMI, o GATT etc. determinem as políticas nacionais do assim chamado Terceiro Mundo" (AHMAD, 1999, p. 5); e o quarto aspecto reside na ideia de incorporação planetária às relações capitalistas de produção.

Recebido em: $\quad$ 20/06/11

Aprovado em: $\quad 18 / 10 / 11$ 